\title{
Low-load high-velocity resistance exercises improve strength and functional capacity in diabetic patients
}

\author{
Rodrigo Celes (1,2), Martim Bottaro (2), Eduardo Cadore (3), Jane Dullius (2), \\ Fabiano Schwartz (2), Filipe Luzine (2) \\ (1) University Center of Federal District, UDF, Brasília, Brazil; (2) University of Brasília, \\ Brasilia, Brazil;(3) Federal University of Rio Grande do Sul, Porto Alegre, RS, Brazil. \\ This article is distributed under the terms of the Creative Commons Attribution Noncommercial License (CC BY-NC 4.0) which permits \\ any noncommercial use, distribution, and reproduction in any medium, provided the original author(s) and source are credited.
}

\begin{abstract}
This study investigated the effects of low-load high-velocity resistance exercises on neuromuscular and functional outcomes in patients with Type 2 diabetes (T2D) during the early-phase of resistance training. Thirty participants with T2D performed 18 training sessions (6 weeks - 3x week) in one of two groups: low-load high-velocity exercises (LLHV, $\mathrm{n}=15$, $62.1 \pm 10.5$ years) or recreational activities (RA, $\mathrm{n}=1556.7 \pm 19.4$ years). LLHV performed resistance exercises with 3x 8reps as fast as possible with 50-60\% 1RM. RA performed light activities. Strength, power, and functional tests were assessed. There was significant increasing in the knee extension peak-torque at $60 \%(7.6 \%)$ and $180 \%(12.2 \%)$, rate of force development in the LLHV group $(\mathrm{P}<0.05)$, whereas there were no changes in the RA group. Significant increases in functional test were observed in the LLHV group $(\mathrm{P}<0.01)$ with no changes in the RA group. In conclusion, the LLHV induced marked improvements in neuromuscular parameters, as well as in the functional capacity of participants with T2D.

Key Words: Type 2 diabetes; power output; rate of force development; rate of velocity development; strength training.
\end{abstract}

Eur J Transl Myol 27 (2): 121-129

Diabetes mellitus is a chronic degenerative endocrine disease that affects millions of people. There are many complications associated with diabetes, such as cardiovascular diseases, peripheral neuropathy, retinopathy, chronic renal failure and impaired mental health. ${ }^{1-3}$ Diabetes is also associated with reduced muscle strength, poor muscle quality, and accelerated loss of muscle mass. ${ }^{4-7}$ Indeed, diabetes mellitus and insulin resistance increase the likelihood of accelerating the aging process and development of frailty syndrome. ${ }^{4}$ 7-10 This process may contribute to increase the risk of falls, institutionalization and disability. ${ }^{11}$

Recently, it has been reported there is a greater decline in muscle strength in elderly patients with Type 2 diabetes when compared with normoglycemic controls. ${ }^{6,12}$ In addition, Leenders et al. ${ }^{5}$ reported that aging patients with Type 2 diabetes presented a greater decline in functional capacity along with the lower-body muscle mass and strength when compared with normoglycemic participants. Thus, besides the metabolic control, effective strategies are needed to prevent the exacerbated loss of strength and functional capacity in aging diabetic patients. Moreover, functional capacity preservation should be especially addressed in aging diabetic patients, because unlike other chronic conditions, diabetes care is dependent on the patients' ability to perform self-care tasks. ${ }^{11}$ Exercise programs including resistance training are one of the cornerstones of diabetes management, together with pharmacological and dietary interventions. ${ }^{13}$ It has been widely shown that resistance training programs, especially those with low-load high-velocity muscle actions during the concentric phase, are effective interventions to improve muscle strength, power output, rate of force development and functional capacity in elderly participants. ${ }^{14-19}$ In the study Bottaro et al. ${ }^{20}$ reported greater increases in functional performance were observed after resistance training performed with explosive muscle actions. In fact, studies have shown that muscle power seems to be a more important predictor of functional performance in elderly adults than muscle strength alone. ${ }^{21,22}$ Despite the effectiveness of low-load high-velocity resistance training on strength performance and functional capacity in the elderly, its effects upon patients with type 2 diabetes remains to be elucidated. Furthermore, although the positive effects of resistance exercises on glycemic control and others 
disorders associated with diabetes have been often investigated, ${ }^{23,24}$ the effects of resistance training on neuromuscular parameters, such as power output and rate of force development (RFD) and rate of velocity development (RVD) are poorly investigated in participants with diabetic's patients. Therefore, the aim of this study was investigate the effects of low-load high-velocity resistance exercises on neuromuscular and functional outcomes in patients with Type 2 diabetes during the early-phase of resistance training. Our hypothesis was that significant strength and functional capacity gains would be observed in the diabetic patients, even after short period of training (i.e., 6 weeks of training).

\section{Material and Methods}

This study was approved by the University Institutional Review Board (035/11).

\section{Participants}

Thirty inactive Type 2 diabetic participants (diagnosed disease for at least ten years) volunteered to participate in the study. The diabetics were selected at random from responders to advertisements placed in health clinics, hospital, public officers, and by word-of-mouth. The volunteers were randomly assigned to either a low-load high-velocity resistance exercises (LLHV) or recreational activities (RA) group. Due to ethical reasons, the Institutional Review Board suggested that all participants should have some type of exercise intervention. Instead a non-exercise control group, to avoid any major treats of internal validity, we chose to have a recreational physical activities group. The recreational activity was performed with low intensity to avoid any kind of overload that could induce any supercompensation in strength or power.

Volunteers were excluded if they were enrolled in another exercise program and those who had less than $85 \%$ attendance in the present study. Therefore, 15 participants in the LLHV and 15 in the RA group successfully concluded the study. All participants were required to, with the exception of their T2D, be apparently healthy, have their T2D under control, and to have been given medical clearance to undertake physical activity and exercise. Additionally, participants were all sedentary and did not perform any kind of physical activity more than once a week for the past six months. A clinical examination was conducted by a physician in all participants to check if they were able to participate in the study. Before signing an informed consent, details about the study were explained to the participants, which included a description of the associated risks and benefits of participation. The study was conducted according to Declaration of Helsinki and was approved by an Institutional Review Board.

\section{Procedures}

Lower-body strength assessment
The right knee extension peak torque (PT) was measured on the Biodex system 3 Isokinetic Dynamometer (Biodex Medical, Inc., Shirley, NY). The calibration of the dynamometer was performed according to the manufacturer's specifications before every testing session. Participants sat upright with the axis of rotation of the dynamometer oriented with the lateral femoral condyle of the right knee. Belts were used to secure the thigh, pelvis, and trunk to the dynamometer chair to prevent additional body movement. The chair and dynamometer settings were recorded to ensure the same positioning for all tests. The flexor torque produced by the relaxed segment was used for gravity correction. Three sets of four knee extension isokinetic concentric contraction at $60 \%$ and $180 \%$ s. Knee extension range of motion was performed between $10^{\circ}$ and $90^{\circ}$, with full extension acting as the reference point. Participants were instructed to fully extend and flex the knee as strong and fast as possible during each set of exercises. In order to assess the rate of force development, three 4-s isometric contractions at $60^{\circ}$ of knee extension were performed $\left(0^{\circ}\right.$ is the full extension). The participants were instructed to fully extend the knee as strong and fast as possible during each set of exercises and the rest intervals among each isometric and dynamic contractions were $60 \mathrm{~s}$, based on the recommendations of Bottaro et al. ${ }^{25}$ Verbal encouragement was given throughout the testing session. The knee strap was released during each rest period to ensure unrestricted blood flow to the quadriceps. The procedures were administered to all participants by the same investigator.

Rate of force development (RFD) and rate of velocity development (RVD)

A software tool on MatLab software 6.5 was developed to estimate RFD and RVD from the file generated by the Biodex software where the signals (angular position, velocity, and torque) were sampled. ${ }^{26}$ Once the original sample rate of the digitized biomechanical signals was 100 samples/s, cubic spline data interpolation was implemented as a tool feature and it was used in order to improve the accuracy. ${ }^{27}$ Thus, the interpolation frequency used was 20,000 samples/s. RFD is usually obtained from the slope of the force-time curve ( $\Delta$ force/ $\Delta$ time), whereas, for intact joint actions as isometric contraction, RFD is calculated as the slope of the joint moment-time curve ( $\Delta$ Torque/ $\Delta$ time $){ }^{28}$ Possible estimates of RFD include time intervals of 0 100, 0-200, and 0-300 ms as well as the interval needed to achieve peak torque. All of the considered intervals are relative to the onset of contraction. Onset of muscle contraction is defined as the time point at which the moment curve exceeded baseline moment by $7 \mathrm{Nm}^{28}$ Estimates of RVD were obtained from the slope of the velocity-time curve ( $\Delta$ Velocity/ $\Delta$ time). According to Brown and Whitehurst, ${ }^{29}$ RVD is movement before matching the predetermined velocity $\left(60 \%\right.$ s and $180^{\circ} / \mathrm{s}$ 
Low-load high-velocity resistance exercises in diabetes

Eur J Transl Myol 27 (2): 121-129

Table 1 - Pre and Post Peak torque (PT) (N.m) on different velocity

\begin{tabular}{|c|c|c|c|c|c|c|}
\hline & Groups & Pre & Post & $\mathrm{F}^{\mathrm{b}}$ & $p^{b}$ & ES \\
\hline \multirow{4}{*}{ Isometric } & LLHV & $146.2 \pm 32.8$ & $157.1 \pm 30.8$ & 5.618 & 0.027 & 0.33 \\
\hline & RA & $149.6 \pm 53.6$ & $158.1 \pm 44.8$ & 2.633 & 0.120 & 0.16 \\
\hline & $\mathrm{F}^{\mathrm{a}}$ & 0.034 & 0.004 & & & \\
\hline & $p^{a}$ & 0.856 & 0.953 & & & \\
\hline \multirow{4}{*}{$60 \%$} & LLHV & $127.0 \pm 47.0$ & $139.9 \pm 51.0$ & 29.213 & 0.000 & 0.27 \\
\hline & RA & $132.6 \pm 37.6$ & $137.5 \pm 32.4$ & 3.45 & 0.078 & 0.13 \\
\hline & $\mathrm{F}^{\mathrm{a}}$ & 0.093 & 0.017 & & & \\
\hline & $p^{a}$ & 0.763 & 0.897 & & & \\
\hline \multirow{4}{*}{$180^{\circ} / \mathrm{s}$} & LLHV & $83.2 \pm 28.4$ & $93.3 \pm 34.6$ & 12.469 & 0.002 & 0.36 \\
\hline & RA & $95.3 \pm 28.9$ & $97.3 \pm 28.4$ & 0.399 & 0.535 & 0.07 \\
\hline & $\mathrm{F}^{\mathrm{a}}$ & 0.979 & 0.083 & & & \\
\hline & $p^{a}$ & 0.334 & 0.777 & & & \\
\hline
\end{tabular}

RA, recreational activities $(n=15)$; LLHV, low-load high-velocity resistance exercises $(n=15)$.

${ }^{\text {a } D i f f e r e n c e ~ b e t w e e n ~ g r o u p s . ~}$

${ }^{\mathrm{b}}$ Difference between time.

for the present study). In other words, RVD is the slope from the point of velocity zero to the point matching the predetermined velocity.

\section{Functional fitness test}

Three components of the Rikli and Jones functional fitness test 30 were selected as a functional performance measure. This particular battery of tests was considered to be an appropriate measurement of the physiologic parameters that were associated with functional mobility in independent elderly adults and would therefore be targeted in the study's intervention. This included lower body strength and agility/dynamic balance. The following test items were conducted: 1) a 30-s chair stand test (the maximum number of times within $30 \mathrm{~s}$ that an individual can rise to a full stand from a seated position, without pushing with the arms) 31 ,2) an 8 -ft up-and-go test (standing up from a chair, walking $8 \mathrm{ft}$ to and around a cone, and walking back to the original position in the shortest possible time) 32, and 3) 6 minute walk test (walk as fast as possible for 6 minutes around a 50 yard's rectangle $-20 \times 5$ yards 33 .

\section{Resistance training intervention}

The participants began by performing sixfamiliarization training sessions over a 2 -week period. ${ }^{34}$
This familiarization period was included for two reasons: 1) initial muscle strength increases at the beginning of a training program may be associated with learning effects, ${ }^{35}$ and 2) a decreased risk of injury would be more likely as most weight training injuries occur during the first 2 weeks. ${ }^{36}$ When the familiarization sessions were completed, the tests of muscle strength and power were conducted, followed by the functional performance fitness tests. Participants were given a 2-day recovery period between each test. The exercise protocols were designed in accordance with published guidelines for resistance training of elderly adults. ${ }^{37}$ The 6 -week training regimen consisted of 18 training sessions, which were divided into three training days/week. For LLHV group the program incorporated 3 sets of 8 repetitions of the following exercises: squat on the Smith machine, lat-pull down, seated knee extension, chest press and seated knee flexion (Righeto®, Free Style e Pro, Campinas/SP, Brazil) which were interspersed by $90 \mathrm{~s}$ recovery intervals. The LLHV group performed all of the exercises with contractions as fast as possible in the concentric phase and 1-2 s in the eccentric phase. The rating of perceived exertion OMNI-RES scale was used to determine the training load. ${ }^{38}$ On the first 9 sessions the OMNI-RES scale was set on 3 (light weight - 


\section{Low-load high-velocity resistance exercises in diabetes}

Eur J Transl Myol 27 (2): 121-129

Table 2 - Rate of force development (RFD) $\left(\mathrm{N} \mathrm{ms}^{-1}\right)$ and rate of velocity development (RVD) $\left({ }^{\circ} / \mathrm{s}^{2}\right)(\mathrm{Mean} \pm \mathrm{SD})$

\begin{tabular}{|c|c|c|c|c|c|}
\hline Intervals & & LLHV & RA & $\mathrm{F}^{\mathrm{a}}$ & $p^{\mathrm{a}}$ \\
\hline \multirow{5}{*}{$\begin{array}{l}\text { RFD 0-100 ms } \\
\text { (Isometric) }\end{array}$} & Pre & $369.3 \pm 218.5$ & $596.0 \pm 404.9$ & 2.803 & 0.11 \\
\hline & Post & $459.2 \pm 220.0$ & $508.6 \pm 331.9$ & 0.175 & 0.681 \\
\hline & $\mathrm{F}^{\mathrm{b}}$ & 2.432 & 1.916 & & \\
\hline & $p^{\mathrm{b}}$ & 0.135 & 0.181 & & \\
\hline & ES & 0.41 & -0.22 & & \\
\hline \multirow{5}{*}{$\begin{array}{l}\text { RFD 0-200 ms } \\
\text { (Isometric) }\end{array}$} & Pre & $316.2 \pm 154.0$ & $449.6 \pm 236.0$ & 2.547 & 0.126 \\
\hline & Post & $396.3 \pm 126.7$ & $429.4 \pm 217.4$ & 0.198 & 0.661 \\
\hline & $F^{b}$ & 6.668 & 0.353 & & \\
\hline & $p^{\mathrm{b}}$ & 0.018 & 0.559 & & \\
\hline & ES & 0.52 & -0.09 & & \\
\hline \multirow{5}{*}{$\begin{array}{l}\text { RFD 0-300 ms } \\
\text { (Isometric) }\end{array}$} & Pre & $271.4 \pm 107.2$ & $364.4 \pm 164.7$ & 2.552 & 0.126 \\
\hline & Post & $328.2 \pm 79.1$ & $350.4 \pm 134.2$ & 0.232 & 0.635 \\
\hline & $F^{b}$ & 7.143 & 0.367 & & \\
\hline & $p^{\mathrm{b}}$ & 0.015 & 0.552 & & \\
\hline & ES & 0.53 & -0.09 & & \\
\hline \multirow{5}{*}{$\begin{array}{l}\text { RVD } \\
\left(180^{\circ} / \mathrm{s}\right)\end{array}$} & Pre & $1569.6 \pm 634.9$ & $2161.2 \pm 958.6$ & 3.006 & 0.098 \\
\hline & Post & $1695.1 \pm 535.3$ & $1688.1 \pm 919.6$ & 0.001 & 0.982 \\
\hline & $\mathrm{F}^{\mathrm{b}}$ & 0.371 & 4.389 & & \\
\hline & $p^{\mathrm{b}}$ & 0.549 & 0.049 & & \\
\hline & ES & 0.20 & -0.49 & & \\
\hline
\end{tabular}

RA, recreational activities $(n=15)$; LLHV, low-load high-velocity resistance exercises $(n=15)$.

${ }^{a}$ Difference between groups.

${ }^{\mathrm{b}}$ Difference between time.

approximately $50 \%$ of $1 \mathrm{RM}$ ) and on the last 9 sessions it was set on six (moderated weight - approximately $60 \%$ of $1 \mathrm{RM})$.

\section{Recreational activities intervention}

Same as LLHV group, the RA participants began by performing six-familiarization training sessions over a 2-week period. This familiarization period was included for RA performed the same number of intervention sections as LLHV group. When the familiarization sessions were completed, the tests of muscle strength and power were conducted, followed by the functional performance fitness tests. Participants were given a 2day recovery period between each test. The RA group performed 18 training sessions alternated one of the followed interventions: 1) $40 \mathrm{~min}$ of very low-intensity walk, 2) $40 \mathrm{~min}$ of dance class, 3) $40 \mathrm{~min}$ of light stretching. The activities performed by the RA group were guided by a trained instructor who was instructed to conduct activities as lightly as possible (low intensity). Participants could not greatly increase their breathing rates (i.e., they could not be panting). 


\section{Low-load high-velocity resistance exercises in diabetes}

Eur J Transl Myol 27 (2): 121-129

Table 3 - Functional capacity outcomes pre and post training (Mean \pm SD)

\begin{tabular}{|c|c|c|c|c|c|c|}
\hline Functional tasks & Groups & Pre & Post & $\mathrm{F}^{\mathrm{b}}$ & $p^{\mathrm{b}}$ & ES \\
\hline \multirow[t]{4}{*}{ 8-Ft up-and-go (s) } & LLHV & $5.5 \pm 0.9$ & $5.2 \pm 0.9$ & 2.85 & 0.102 & -0.33 \\
\hline & RA & $5.2 \pm 0.7$ & $5.2 \pm 0.7$ & 0.079 & 0.780 & 0.00 \\
\hline & $\mathrm{F}^{\mathrm{a}}$ & 0.796 & 0.031 & & & \\
\hline & $p^{\mathrm{a}}$ & 0.38 & 0.862 & & & \\
\hline \multirow{4}{*}{$\begin{array}{l}\text { 30s Chair stand } \\
\text { (rep) }\end{array}$} & LLHV & $16.3 \pm 4.2$ & $20.2 \pm 5.3$ & 15.777 & 0.000 & 0.93 \\
\hline & RA & $15.1 \pm 3.6$ & $15.8 \pm 4.3$ & 0.548 & 0.465 & 0.19 \\
\hline & $\mathrm{F}^{\mathrm{a}}$ & 0.756 & 6.209 & & & \\
\hline & $p^{\mathrm{a}}$ & 0.392 & 0.019 & & & \\
\hline \multirow[t]{4}{*}{6 min walk $(\mathrm{m})$} & LLHV & $623.8 \pm 72.9$ & $675.0 \pm 67.8$ & 12.777 & 0.002 & 0.7 \\
\hline & RA & $584.2 \pm 73.5$ & $596.9 \pm 48.2$ & 0.849 & 0.366 & 0.17 \\
\hline & $\mathrm{F}^{\mathrm{a}}$ & 1.816 & 10.987 & & & \\
\hline & $p^{\mathrm{a}}$ & 0.191 & 0.003 & & & \\
\hline
\end{tabular}

RA, recreational activities ( $\mathrm{n}=15)$; LLHV, low-load high-velocity resistance exercises $(\mathrm{n}=15)$.

${ }^{\mathrm{a} D i f f e r e n c e ~ b e t w e e n ~ g r o u p s . ~}$

${ }^{\mathrm{b}}$ Difference between time.

\section{Statistical analysis}

Descriptive statistics were expressed as means $( \pm \mathrm{SD})$. The normality of data was tested by Shapiro-Wilk test. The possible effects of training were tested by a 2-way mixed factor ANOVA [group (LLHV and RA) x time (pre and post-test)] for all dependent variable followed by the LSD post-hoc procedure whenever necessary. Due to the initial difference, comparison between groups was determined by the analysis of covariance (ANCOVA) in the PT, RFD and RVD variables. The Effect Size (ES) was calculated from Pre to Posttest by the formula

$$
\begin{aligned}
& \mathrm{ES}=\frac{\text { Posttest Mean-Pretest Mean }}{\text { Pretest SD }} \\
& \left(\mathrm{SD}=\text { standart deviation). }{ }^{39}\right.
\end{aligned}
$$

The probability level of statistical significance was set at $\alpha<0.05$. All calculations were performed using SPSS (version 19.0).

\section{Results}

Thirty participants were divided in two groups: LLHV $(\mathrm{n}=15,62.1 \pm 10.5$ years, $161.5 \pm 8.6 \mathrm{~cm}, 75.1 \pm 16.7 \mathrm{~kg}$ - mean blood glucose $134.2 \pm 28.09 \mathrm{mg} / \mathrm{dl}$ ) and RA $(\mathrm{n}=15,56.7 \pm 19.4$ years, $166.2 \pm 7.4 \mathrm{~cm}, 77.7 \pm 18.0 \mathrm{~kg}$ - mean blood glucose $163.3 \pm 48.05 \mathrm{mg} / \mathrm{dl}$ ).

\section{Strength performance}

The strength performance variables are presented in Table 1 and 2. Before the training period, there were no significant differences between groups in the isokinetic peak torques, as well as in the RFD variables. There were significant increases, but trivial in peak torque at $60 \%$ s $(7.6 \%, \mathrm{P}<0.001, \mathrm{ES}=0.27)$ and $180 \%(12.2 \%$, $\mathrm{P}<0.01,0.36)$ in the LLHV group, whereas no significant changes were observed in the RA group ( $3.7 \%$ and $2.1 \%$, respectively). After the intervention period, there were no significant differences $(\mathrm{P}>0.005)$. (Table 1). Regarding the RFD variables, there were significant increases in the LLHV group in RFD at 0$200 \mathrm{~ms} \quad(25.3 \%)$ and $0-300 \mathrm{~ms} \quad(20.9 \%)$ intervals $(\mathrm{P}<0.05)$, whereas no changes were observed in the RA group. Regarding the RVD (at $180 \%$ ), there was a significant reduction in the RA $(-21.89 \%, \mathrm{P}<0.05)$, whereas a no significant increase $(8 \%)$ in the LLHV was reported. No significant differences between groups in the RFD and RVD variables were observed after training (Table 2).

\section{Functional capacity}

The functional capacity variables are presented in the Table 3. Before the training period, there were no 
significant differences between groups in the $6 \mathrm{~min}$ walking test, stand up from a chair ability, and time-upand-go test. After the exercise intervention, there was significant improvement in the $6 \mathrm{~min}$ walking test performance in the LLHV group $(8.2 \% \quad \mathrm{P}<0.01)$, whereas no significant change was observed in the RA group (2.2\%). In addition, only the LLHV group increased the stand up from a chair ability $(24.2 \%$, $\mathrm{P}<0.001)$, while no change was observed in the RA group $(4.8 \%, \mathrm{P}>0.05)$. Moreover, no significant changes were observed in both LLHV $(-4.6 \%, \mathrm{P}=0.1)$ and RA ($0.6 \%, \mathrm{P}=0.78)$ groups in the time-up-and-go test performance. After the interventions, the LLHV group showed significant greater performance in the $6 \mathrm{~min}$ walking test $(\mathrm{P}<0.05)$, and in the stand from a chair ability test $(\mathrm{P}<0.05)$ while no significant change was observed in RA group.

\section{Discussion}

The primary findings of the present study was that only 6 weeks of low-load high-velocity resistance exercises improved muscle strength, power output, and functional capacity in Type 2 diabetics participants. In addition, physical activity intervention composed by lowintensity walking, dancing classes and stretching exercises did not induce any changes in the strength, power, and functional capacity. It has been shown that patients with Type 2 diabetes have a greater decline in the muscle strength and functional capacity, as well as accelerated loss of muscle mass when compared with normoglycemic controls. ${ }^{4-7},{ }^{12}$. Indeed, diabetes complications such as peripheral vascular diseases and peripheral neuropathy are associated with poor gait ability, impaired balance and greater risk of falls. ${ }^{40-42}$ Thus, preservation of functional capacity should be especially addressed in aging diabetic patients, because these individuals are at greater risk of development of frailty syndrome, institutionalization and disability. $8,10,11$ Nevertheless, the effects of resistance exercise intervention upon functional outcomes in participants with Type 2 diabetes are poorly investigated. In the present study we choose to test the effectiveness of lowload high-velocity resistance exercises in patients with diabetes, because in elderly, it has been shown that this type of resistance training promotes greater functional outcomes enhancements than traditional resistance training. ${ }^{16-20,43}$ For example, Bottaro, Machado have shown greater improvement in the sit-to-stand ability after high-velocity resistance training compared with traditional resistance training (42.8 vs. $6.05 \%$, respectively). ${ }^{20}$ Recently, Geirsdottir et al. ${ }^{44}$ showed that 12 weeks of traditional resistance training improved $\sim 13 \%$ the 6 minutes walking performance in diabetic elderly Icelanders. Different from Geirsdottir et al., ${ }^{44}$ using high-velocity instead of traditional resistance training, the present study also reported an improvement $(8 \%)$ on the 6 minutes walking performance that was achieved in only half time of the training period (i.e. 6 weeks). Thus, our findings suggest that the three times a week low-load high-velocity resistance training is an effective way to promote rapid functional capacity increases in subject with Type 2 diabetes individuals, who are at greater risk of functional and neuromuscular declines during the aging process. A unique finding of the present study was the increase in the capacity of rapid force development (RFD) in the diabetic patients. Along with the increase in peak torque at $60 \%$, the present study demonstrates that the patients with diabetes also improved peak torque at $180^{\circ}$ s, as well as RFD in different time intervals (i.e., $0-200 \mathrm{~ms}$ and 0 $300 \mathrm{~ms})$. These findings are especially important because RFD seems to be more associated with the functional outcomes than maximal strength $\mathrm{per} \mathrm{se}^{45}$ Functional activities in daily life, as well as the capacity to prevent falls are actions characterized by a limited time to produce force, which is considerably less time than it takes to develop the maximal force..$^{28,46}$ Moreover, muscle power decreases more rapidly than maximal strength during the aging. ${ }^{47}$ Furthermore, in aging patients with Type 2 diabetes, besides the exacerbated decline in muscle strength, ${ }^{5,6}$ it has been shown that this population has a lower capacity to improve strength than normoglycemic individuals. ${ }^{48}$ Thus, effective strategies to promote neuromuscular gains in diabetics is needed, and the present findings showed that the low-load high-velocity resistance exercises were able to improve not only maximal strength, but also RFD in this population in just six weeks of resistance training intervention. Rate of velocity development (RVD) represents the acceleration of a limb, which refers to the ability to reach top speed quickly, and may be also advantageous to the human performance. ${ }^{29,49}$ In the present study, there was a significant reduction in RVD in the RA group, whereas a non-significant increase was observed in the LLHV group. It can be speculated that maintaining the ability to rapidly increase the velocity of motion (RVD) may allow the aging diabetic participants resume the stability against unbalances. However, although muscle power output and RFD are strongly associated with the functional capacity in elderly, ${ }^{21,28,46}$ it seems that this the first study to investigate the effects of resistance training on the RVD in patients with Type 2 diabetes. Thus, the relationship between RVD and functional capacity in aging participants need to be further investigated. In addition, future studies are granted in order to compare the effects of low-load high-velocity resistance exercises vs traditional resistance training (i.e., moderate/heavy load and slow concentric phase) in functional capacity outcomes in diabetics. In despite of this limitation, it seems that this is the first study investigating the effects of low-load high velocity resistance exercises in diabetics patients during the early-phase of the resistance training period. Another possible limitation of the present study was the absence of a control group not performing any type of physical 
activity. In summary, the present study showed that a short-term high-velocity resistance exercises performed with low intensity (i.e., $\geq 60 \%$ 1RM) induced improvements in muscle strength and power parameters, as well as in functional capacity of participants type 2 diabetes. Moreover, the recreational physical activity intervention composed of low-intensity walking, dancing classes and stretching exercise were not sufficient stimulus to induce the same benefits. Although the group LLHV obtained significant improvements in PT, it should be noted that the magnitude of these gains are trivial (ES <0.50). Perhaps longer-lasting interventions (more than 6 weeks) can lead to greater gains. From a practical standpoint, a high-velocity resistance exercises intervention using light intensity (i.e., 50-60\% of 1RM) should be include in the exercise programs in order to improve strength, power output, and functional capacity in subject with type 2 diabetes.

\section{List of acronyms}

T2D - type 2 diabetes

LLHV - low-load high-velocity resistance exercises

$\mathrm{RA}$ - recreational activities

RFD - rate of force development

RVD - rate of velocity development

PT - peak torque

\section{Author's contributions}

$\mathrm{RC}$ and $\mathrm{MB}$ conceived and supervised the project. RC, $\mathrm{MB}$ and EC helped the elaboration of the methodology and the prototype characterization. RC, JD and FL performed the experiments and optimized the methodology. RC and FS contributed to data analysis and interpreted the results. RC wrote the manuscript and $\mathrm{MB}$ and EC helped in revising it.

\section{Acknowledgments}

This study was partially supported by the Council for the Research Development (CNPq) and by the Coordination for the Improvement of Higher Level Personnel (Capes).

\section{Conflict of Interest}

The authors declare no conflict of interests.

\section{Corresponding Author}

Rodrigo Souza Celes, SQNW 310, B, apt ${ }^{\circ} 416$, 70687-210 Brasília, DF Brasil / Brazil.

Phone: +55 61981340377

E-mail: celes.rodrigo@gmail.com

\section{E-mails of coAuthors}

Martim Bottaro: martim@unb.br;

Eduardo Cadore: edcadore@yahoo.com.br;

Jane Dullius: janedullius@gmail.com;

Fabiano Schwartz: fabiano.schwartz@camara.gov.br;

Filipe Luzine: filipe.luzine@hotmail.com;

\section{References}

1. Maiorana A, O'driscoll G, Goodman C, et al. Combined aerobic and resistance exercise improves glycemic control and fitness in type 2 diabetes. Diabetes Res Clin Pract 2002;56:115-23.

2. Blaum CS, West NAHaan MN. Is the metabolic syndrome, with or without diabetes, associated with progressive disability in older mexican americans? J Gerontol A Biol Sci Med Sci 2007;62:766-73.

3. Reeves MJ, Vaidya RS, Fonarow GC, et al. Quality of care and outcomes in patients with diabetes hospitalized with ischemic stroke: Findings from get with the guidelines-stroke. Stroke 2010;41:e409-17.

4. Garg PK, Liu K, Tian L, et al. Physical activity during daily life and functional decline in peripheral arterial disease. Circulation 2009;119:251-60.

5. Leenders M, Verdijk LB, Van Der Hoeven L, et al. Patients with type 2 diabetes show a greater decline in muscle mass, muscle strength, and functional capacity with aging. J Am Med Dir Assoc 2013;14:585-92.

6. Park SW, Goodpaster BH, Strotmeyer ES, et al. Accelerated loss of skeletal muscle strength in older adults with type 2 diabetes: The health, aging, and body composition study. Diabetes Care 2007;30:1507-12.

7. Volpato S, Bianchi L, Lauretani F, et al. Role of muscle mass and muscle quality in the association between diabetes and gait speed. Diabetes Care 2012;35:1672-9.

8. Kahn AJ. Central and peripheral mechanisms of aging and frailty: A report on the 8th longevity consortium symposium, santa fe, new mexico, may 16-18, 2007. J Gerontol A Biol Sci Med Sci 2007;62:1357-60.

9. Padula RS, Comper ML, Moraes SA, et al. The work ability index and functional capacity among older workers. Braz J Phys Ther 2013;17:382-91.

10. Sinclair A, Morley JE, Rodriguez-Manas L, et al. Diabetes mellitus in older people: Position statement on behalf of the international association of gerontology and geriatrics (iagg), the european diabetes working party for older people (edwpop), and the international task force of experts in diabetes. J Am Med Dir Assoc 2012;13:497-502.

11. Abdelhafiz AH, Sinclair AJ. Management of type 2 diabetes in older people. Diabetes Ther 2013;4:13-26.

12. Alvarenga P, Pereira SAnjos D. Mobilidade funcional e função executiva em idosos diabéticos e não diabéticos. Rev Bras Fisioter 2010;14:491-6.

13. Robinson CC, Barreto RP, Sbruzzi GPlentz RD. The effects of whole body vibration in patients with type 2 diabetes: A systematic review and 
meta-analysis of randomized controlled trials. Braz J Phys Ther 2016;20:4-14.

14. Correa CS, Laroche DP, Cadore EL, et al. 3 different types of strength training in older women. Int J Sports Med 2012;33:962-9.

15. Henwood TR, Riek STaaffe DR. Strength versus muscle power-specific resistance training in community-dwelling older adults. J Gerontol A Biol Sci Med Sci 2008;63:83-91.

16. Pereira A, Izquierdo M, Silva AJ, et al. Effects of high-speed power training on functional capacity and muscle performance in older women. Exp Gerontol 2012;47:250-5.

17. Sayers SP. High-speed power training: A novel approach to resistance training in older men and women. A brief review and pilot study. J Strength Cond Res 2007;21:518-26.

18. Sayers SP. High velocity power training in older adults. Current Aging Science 2008;1:62-67.

19. Sayers SP, Gibson K. High-speed power training in older adults: A shift of the external resistance at which peak power is produced. J Strength Cond Res 2014;28:616.

20. Bottaro M, Machado SN, Nogueira W, et al. Effect of high versus low-velocity resistance training on muscular fitness and functional performance in older men. Eur J Appl Physiol 2007;99:257-64.

21. Casas-Herrero A, Cadore EL, Zambom-Ferraresi F, et al. Functional capacity, muscle fat infiltration, power output and cognitive impairment in institutionalized frail oldest old. Rejuvenation Res 2013;16:396-403.

22. Reid KFFielding RA. Skeletal muscle power: A critical determinationat of physical functioning in older adults. Exerc Sport Sci Rev 2012;40:1-12.

23. Castaneda C, Layne JE, Munoz-Orians L, et al. A randomized controlled trial of resistance exercise training to improve glycemic control in older adults with type 2 diabetes. Diabetes Care 2002;25:2335-41.

24. Umpierre D, Ribeiro PA, Kramer CK, et al. Physical activity advice only or structured exercise training and association with hba1c levels in type 2 diabetes: A systematic review and meta-analysis. JAMA 2011;305:1790-9.

25. Bottaro M, Russo A, Oliveira RJ. The effects of rest interval on quadriceps torque during an isokinetic testing protocol in elderly. J Sports Sci Med 2005;4: 285-90.

26. Schwartz FP, Oliveira FA, Bottaro MCeles RS. Análise de estacionaridade de sinal eletromiográfia de superfície nas fases de exercício isocinético de extensão do joelho. Braz J Biom Eng 2012;28:4452.

27. De Boor CA, A practical guide to splines. 1978, New York: Springer-Verlag.

28. Aagaard P, Simonsen EB, Andersen JL, et al. Neural adaptation to resistance training: Changes in evoked v-wave and h-reflex responses. J Appl Physiol 2002;92:2309-18.

29. Brown LEWhitehurst M. The effect of short-term isokinetic training on force and rate of velocity development. J Strength Cond Res 2003;17:88-94.

30. Rikli REJones CJ. Developing and validation of a functional fitness test for community-residing older adults. J Aging Phy Act 1999;7:129.

31. Rosie JTaylor D. Sit-to-stand as home exercise for mobility-limited adults over 80 years of age-grandstand system may keep you standing? Age Ageing 2007;36:555-62.

32. Jernigan SD, Pohl PS, Mahnken JDKluding PM. Diagnostic accuracy of fall risk assessment tools in people with diabetic peripheral neuropathy. Phys Ther 2012;92:1461-1470.

33. Marcus RL, Smith A, Morrell G, et al. Comparison of combined aerobic and high-force eccentric resistance exercise with aerobic exercise only for people with type 2 diabetes mellitus. Phys Ther 2008;88:1345-1354.

34. Hunter GR, Wetzstein CJ, Mclafferty CL, Jr., et al. High-resistance versus variable-resistance training in older adults. Med Sci Sports Exerc 2001;33:1759-64.

35. Hakkinen K, Kraemer WJ, Newton RUAlen M. Changes in electromyographic activity, muscle fibre and force production characteristics during heavy resistance/power strength training in middle-aged and older men and women. Acta Physiol Scand 2001;171:51-62.

36. Shaw CE, Mccully KKPosner JD. Injuries during the one repetition maximum assessment in the elderly. J Cardiopulm Rehabil 1995;15:283-7.

37. Acsm. American college of sports medicine position stand. Progression models in resistance training for healthy adults. Med Sci Sports Exerc 2009;41:687-708.

38. Robertson RJ, Goss FL, Rutkowski J, et al. Concurrent validation of the omni perceived exertion scale for resistance exercise. Med Sci Sports Exerc 2003;35:333-41.

39. Rhea MR. Determining the magnitude of treatment effects in strength training research through the use of the effect size. J Strength Cond Res 2004;18:918-20.

40. Powell MW, Carnegie DHBurke TJ. Reversal of diabetic peripheral neuropathy with phototherapy (mire) decreases falls and the fear of falling and improves activities of daily living in seniors. Age Ageing 2006;35:11-6.

41. Wray LA, Ofstedal MB, Langa KMBlaum CS. The effect of diabetes on disability in middle-aged and older adults. J Gerontol A Biol Sci Med Sci 2005;60:206-11.

42. Ko SU, Stenholm S, Chia CW, et al. Gait pattern alterations in older adults associated with type 2 diabetes in the absence of peripheral neuropathy-- 


\section{Low-load high-velocity resistance exercises in diabetes}

Eur J Transl Myol 27 (2): 121-129

results from the baltimore longitudinal study of aging. Gait Posture 2011; 34:548-52.

43. Henwood TRTaaffe DR. Detraining and retraining in older adults following long-term muscle power or muscle strength specific training. J Gerontol A Biol Sci Med Sci 2008; 63:751-8.

44. Geirsdottir OG, Arnarson A, Briem K, et al. Effect of 12-week resistance exercise program on body composition, muscle strength, physical function, and glucose metabolism in healthy, insulinresistant, and diabetic elderly icelanders. J Gerontol A Biol Sci Med Sci 2012; 67:1259-65.

45. Skelton DA, Young A, Greig CAMalbut KE. Effects of resistance training on strength, power, and selected functional abilities of women aged 75 and older. J Am Geriatr Soc 1995; 43:1081-7.

46. Suetta C, Aagaard P, Rosted A, et al. Traininginduced changes in muscle csa, muscle strength, emg, and rate of force development in elderly subjects after long-term unilateral disuse. J Appl Physiol 2004;97:1954-61.

47. Izquierdo M, Ibanez J, Gorostiaga E, et al. Maximal strength and power characteristics in isometric and dynamic actions of the upper and lower extremities in middle-aged and older men. Acta Physiol Scand 1999;167: 57-68.

48. Ibanez J, Gorostiaga EM, Alonso AM, et al. Lower muscle strength gains in older men with type 2 diabetes after resistance training. J Diabetes Complications 2008; 22:112-8.

49. Nguyen D, Brown LE, Coburn JW, et al. Effect of delayed-onset muscle soreness on elbow flexion strength and rate of velocity development. J Strength Cond Res 2009;23:1282-6. 